
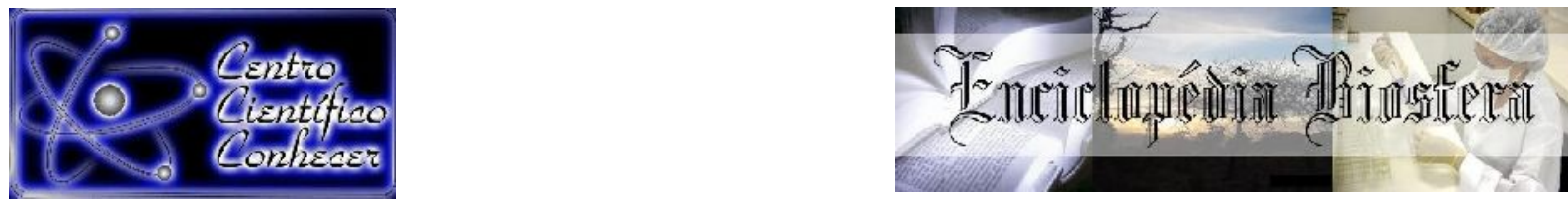

\title{
CONDIÇÕES DE VIDA, TRABALHO E SAÚDE: UM ESTUDO DE CASO SOBRE MULHERES COLETORAS DE RECICLÁVEIS EM DUAS COOPERATIVAS DE MARINGÁ-PR
}

Brenda Marjory Lopes Correa ${ }^{1}$, Caroline Urias Challouts ${ }^{2}$, Marcelo Picinin Bernuci ${ }^{2}$, Tânia Maria Gomes da Silva ${ }^{4}$

${ }^{1}$ Acadêmica do Curso de Psicologia, Universidade Cesumar (UniCesumar). Bolsista voluntária PVIC/ICETI-UniCesumar.

${ }^{2}$ Graduada em Engenharia Civil. Mestranda no Programa de Pós-graduação em Promoção da Saúde pela Universidade Cesumar (UniCesumar). Bolsista pela Coordenação de Aperfeiçoamento de Pessoal de Nível Superior (CAPES).

${ }^{3}$ Co-orientador, Doutor em Biologia, Professor Permanente do Programa de Pósgraduação em Promoção da Saúde na Universidade Cesumar (UniCesumar), Maringá (PR).Bolsista produtividade em Pesquisa do Instituto Cesumar de Ciência, Tecnologia e Inovação (Iceti)

${ }^{4}$ Orientadora, Doutora em História, Professora Permanente do Programa de Pósgraduação em Promoção da Saúde na Universidade Cesumar (UniCesumar), Maringá (PR).

E-mail: tania.gomes@unicesumar.edu.br Bolsista produtividade em Pesquisa do Instituto Cesumar de Ciência, Tecnologia e Inovação (Iceti)

\section{Recebido em: 15/11/2021 - Aprovado em: 15/12/2021 - Publicado em: 30/12/2021 DOI: 10.18677/EnciBio_2021D19}

\section{RESUMO}

A presente pesquisa é de natureza exploratória-descritiva e abordagem qualitativa. Buscou-se conhecer as condições de vida e de trabalho de mulheres coletoras de materiais recicláveis de duas cooperativas de Maringá-PR. O objetivo foi perceber se elas enfrentam alguma situação de violência doméstica ou no trabalho; se entendem que o preconceito de gênero e classe são causadores de sofrimento psíquico e apreender nas narrativas as representações da violência. Foram realizadas 17 entrevistas semiestruturadas, compostas por perguntas norteadoras, na sede de duas cooperativas, em horário comercial, nos meses de maio a agosto de 2019. Os depoimentos foram transcritos na íntegra, interpretados na perspectiva da análise de conteúdo de Bardin. A sustentação teórica foram os estudos de gênero, notadamente numa interface com a saúde. Observou-se que as mulheres vivem imersas em uma cultura patriarcal que naturaliza a superioridade dos homens e, de certo modo, legitima a violência tanto no ambiente laboral quanto familiar.

PALAVRAS-CHAVE: mulheres coletoras; qualidade de vida; saúde; violência. 


\title{
LIFE, WORK AND HEALTH CONDITIONS OF WOMEN WASTE PICKERS IN COOPERATIVES IN MARINGÁ-PR: GENDER NARRATIVES
}

\begin{abstract}
The present research is exploratory-descriptive in nature and qualitative in approach. It sought to understand the living and working conditions of women waste pickers from two cooperatives in Maringá-PR. The objective was to understand if they face any situation of domestic violence or violence at work; if they understand that gender and class prejudice cause psychological suffering and to apprehend in their narratives the representations of violence. Seventeen semi-structured interviews were conducted, composed of guiding questions, at the headquarters of two cooperatives, during business hours, from June to August 2019. The statements were transcribed in full, interpreted from the perspective of Bardin's content analysis The theoretical underpinning was gender studies, notably in an interface with health. It was observed that women live immersed in a patriarchal culture that naturalizes the superiority of men and, in a way, legitimizes violence in both work and family environments.
\end{abstract}

KEYWORDS: health; quality of life; violence; women collectors.

\section{INTRODUÇÃO}

Ao contrário do que ocorria nas sociedades agrárias, urbanas e de industrialização nascentes, geralmente estáveis, na contemporaneidade o mundo do trabalho é cada vez mais dinâmico e sofre impactos diretos e indiretos das trajetórias seguidas pelos sistemas produtivos. O fortalecimento do modelo neoliberal, em ascensão desde a década de 1980, tem levado à transição de uma sociedade de produtividade industrial para uma sociedade cada vez mais de serviço, marcada por desemprego e precarização do trabalho (POCHEMAN, 2020). A precarização do trabalho é condição inerente ao capitalismo e uma de suas características ontológicas, estando diretamente relacionada ao processo de reestruturação produtiva, que gera formas de flexibilização dos vínculos empregatícios, das jornadas e das condições de trabalho cada vez mais informais (COELHO et al., 2016).

Um exemplo de trabalho informal é a coleta de material reciclável, tipo de atividade cada vez mais visível nestes tempos em que as pessoas buscam adquirir produtos não mais apenas para a sobrevivência. Hiperconsumo e hedonismo tornam 0 ato de consumir algo desenfreado, com os indivíduos buscando, a todo custo, a satisfação de seus desejos imediatos (ADERALDO et al., 2020).

O trabalho de coleta de reciclável inclui catar, separar, transportar, acondicionar e, às vezes, beneficiar os resíduos sólidos para reutilizar ou reciclar. Globalmente, em torno de 15 milhões de pessoas trabalham no setor, sendo quase um milhão no Brasil; muitas organizadas em cooperativas, associações ou empresas sociais (COELHO et al., 2016). Embora também expostos a riscos, acidentes e exploração, os trabalhadores vinculados a alguma cooperativa geralmente apresentam melhores condições de trabalho do que aqueles que exercem a atividade de forma independente, atuando nas ruas e nos lixões. Estes últimos, por exercerem a atividade de forma mais livre, estão maisexpostos às doenças por não usarem equipamentos de proteção e por trabalharem sem qualquer suporte dos poderes públicos. Além disso, um agravante é que trabalhadores da reciclagem tendem a ter baixa escolaridade, o que compromete a mudança de condição social por meio da 
inserção no mercado formal (SOUZA; SANTOS, 2020; LIMA, 2021).

No Brasil, embora os coletores de recicláveis existam desde muito antes de serem implantadas políticas públicas para o setor (BARBOSA et al., 2014), somente em 2002 o Brasil assegurou o direito ao registro na Classificação Brasileira de Ocupação (CBO) e reconheceu esta atividade profissional (DIAS et al., 2018). Todavia, o registro na $\mathrm{CBO}$ não impede que eles continuem atuando na ampla informalidade e desprovidos dos direitos trabalhistas aos quais fazem jus (COSTA; CHAVES, 2013).

Estudos como os de Pereira et al. (2012) destacaram os impactos do trabalho de coleta de recicláveis sobre a saúde e a qualidade de vida dos trabalhadores do setor. Assim, além dos preconceitos e estigmas sociais (NASCIMENTO, 2016), eles também estão expostos a riscos, devido à infraestrutura inadequada das cooperativas e ao desconhecimento de medidas de biossegurança; ao contato com insetos, material contaminado e perfurocortantes (SOUZA; SANTOS, 2020).

Nas cooperativas de reciclagem as mulheres são presença expressiva. Desde a década de 60 , com o processo crescente de urbanização e as consequentes mudanças na estrutura das famílias, notadamente a queda nas taxas de fecundidade, as mulheres tiveram maior acesso ao trabalho, especialmente no setor informal. Segundo o Movimento Nacional dos Catadores de Materiais Recicláveis (MNCR), as mulheres representam em torno de $70 \%$ da mão-de-obra do setor e são responsáveis diretas pelo sustento de cerca de 700 mil crianças (MNCR, 2014; 2019).

A despeito desta contribuição significativa, muitas preferem se apresentar como doméstica ou trabalhadora do lar ao invés de coletoras de recicláveis (MNCR, 2014). Isto ocorre devido ao resultado da cristalização do imaginário acerca da divisão sexual do trabalho, que delega às mulheres a responsabilidade pelos trabalhos no mundo privado, mas também, como foi possível depreender das narrativas colhidas neste estudo, porque o trabalho de reciclagem é muito desvalorizado e a pessoa que exerce esta atividade costuma ser estigmatizada, sofrer humilhações, maus-tratos e desprezo social (NASCIMENTO, 2016).

Considerando-se que o preconceito social é uma violência, que estar exposta a violência de qualquer tipologia compromete a qualidade de vida e, consequentemente, causa maior vulnerabilidade ao adoecimento (SILVA et al., 2018), o objetivo desta pesquisa foi identificar as condições de vida e de trabalho de mulheres coletoras de materiais recicláveis em duas cooperativas de Maringá-PR, visando perceber se elas enfrentam situação de violência, seja no ambiente doméstico ou no trabalho; avaliar se entendem que os preconceitos causam sofrimento físico e psíquico e, ainda, observar nas narrativas as representações da violência.

\section{MATERIAL E MÉTODOS}

Tratou-se de pesquisa do tipo exploratório-descritivo e de abordagem qualitativa. Segundo Gil (2008, p 27), as pesquisas exploratórias "[..] têm como principal finalidade desenvolver, esclarecer e modificar conceitos e ideias, tendo em vista a formulação de problemas mais precisos ou hipóteses pesquisáveis para estudos posteriores". Ainda segundo este mesmo autor, a pesquisa qualitativa depende de muitos fatores como as ferramentas de pesquisas e as hipóteses teóricas que delimitam a investigação, além do fato de ter como objetivo atingir aspectos mais significativos e abrangentes em comparação com a análise quantitativa, por 
exemplo. Assim, o foco não era detectar números, mas antes conhecer as representações e práticas das trabalhadoras.

Em Maringá existem quatro cooperativas vinculadas à Associação de Reciclagem Popular e Solidária (ARPSOL), entidade de defesa dos direitos sociais que atua no município desde o ano de 2014. Destas, foram escolhidas duas para local de estudo.

Após contato inicial com a representante da Arpesol foi feita a primeira visita às cooperativas para conhecer o local e as trabalhadoras. Num segundo momento, elas foram convidadas para uma breve reunião em que receberam explicações sobre os propósitos da pesquisa e o convite para integrá-la. Não houve dificuldade no recrutamento e todas se mostraram dispostas a participar.

As entrevistas foram individuais, em horário comercial e gravadas com a ajuda de um aparelho celular. Foram realizados nove encontros, entre maio a agosto de 2019. O ponto de saturação, momento em que as narrativas não apresentam informações novas, foi atingido com 15 depoimentos, mas buscando seguir o projeto inicial de pesquisa, foram realizadas 20 entrevistas. Destas, foram utilizadas 17 . Foram descartadas as entrevistas de três haitianas que, possivelmente pelo pouco domínio da língua portuguesa, deram respostas pouco elucidativas. Os encontros seguiram um roteiro norteador contendo 22 perguntas de natureza aberta que serviu como uma espécie de pró-memória aos entrevistadores (CARDANO, 2017).

Os dados foram analisados qualitativamente, de modo a obter uma compreensão detalhada do fenômeno, seguindo o modelo de análise de conteúdo proposto por Bardin (2016) e interpretadas segundo os pressupostos teóricos dos estudos feministas e de gênero, notadamente numa interface com a saúde (SCHRABIERT et al., 2005). As narrativas foram transcritas da maneira como foram expressas, respeitando as hesitações e erros da fala, mas, na transcrição, foram retiradas as repetições desnecessárias, a fim de tornar o texto mais adequado à leitura, num processo de transcrição (MEIHY; SEAWRIGHT, 2020).

A transcrição respeitou o nível linguístico, paralinguístico e extralinguístico, de modo a expressar tudo o que foi falado pelas entrevistadas, respeitando coloratura emocional das narrativas, para que as mesmas fossem impressas na documentação transcrita, auxiliando na interpretação dos resultados, permitindo compreender as emoções expressadas pelas entrevistadas (CARDANO, 2017).

O estudo foi aprovado pelo Comitê de Ética da Universidade Cesumar, sob o parecer número 2.965.080/2019. Todas as participantes assinaram o Termo de Consentimento Livre e Esclarecido. As integrantes desta pesquisa não receberam nenhum pagamento pela participação no estudo.

\section{RESULTADOS E DISCUSSÃO \\ Quem são as mulheres que participaram da pesquisa e quais suas percepções sobre o ambiente de trabalho?}

Inicialmente, para conhecer o perfil das voluntárias, foram realizados questionamentos que permitiram conhecer faixa etária, grau de instrução, raça/cor da pele autodeclarada, cidade de residência e estado civil. Do total da amostra, 35\% tinham idade acima de 40 anos; 35\% entre 30 e 39 anos; enquanto $30 \%$ tinham idades entre 20 e 29 anos. As cooperativas foram denominadas: Coop. 1 e Coop.2, sendo que $65 \%$ das entrevistadas se encontravam na primeira enquanto 35\% estavam na Coop. 2. 
Quanto ao grau de instrução das voluntárias, 71\% afirmaram ter o ensino fundamental incompleto e $23 \%$ o ensino médio incompleto, as demais apresentavam níveis variados de escolaridade. Em relação a cor, $59 \%$ das voluntárias se autodeclararam negras, pardas ou morenas, 35\% preferiram não responder enquanto $6 \%$ se assumiam brancas. Referente à cidade de residência, $47 \%$ das entrevistadas informaram residir em Maringá, enquanto as demais viviam em cidades vizinhas. Sobre o estado civil das mulheres ouvidas, $53 \%$ viviam em união estável; $24 \%$ eram casadas; $17 \%$ estavam separadas e $6 \%$ eram solteiras.

De acordo com os dados, $88 \%$ das entrevistadas disseram que gostam de trabalhar nas cooperativas, mesmo apontando aspectos negativos. Entre as que não gostam o motivo alegado foi o fato dessa modalidade de trabalho não ser enquadrada no regime celetista, que trata das regras da Consolidação das Leis do Trabalho (CLT). Segundo Oliveira et al. (2017), a falta de políticas públicas que incentivem a reciclagem de resíduos corrobora com o aumento do trabalho autônomo e informal, além de ser pouco organizado e atingir, na maioria das vezes, as pessoas em situação de pobreza.

A informalidade do trabalho, apontada pelas entrevistadas, é marcada pela precarização, na qual trabalhadores têm seus direitos fragilizados, tornando-se cada vez mais vulneráveis ao adoecimento e à diminuição da qualidade de vida (ANTUNES; PRAUN, 2015). Soma-se a isso o fato do trabalho nas cooperativas apresentar riscos químicos, biológicos, físicos, ergonômicos, psicossociais, mecânicos e de acidentes (FONTANA et al., 2015).

O ambiente de trabalho é o espaço artificial no qual o trabalhador passa grande parte do seu tempo (ODDONE et al., 2020), de modo que é de extrema importância a construção e manutenção de um ambiente laboral propício à qualidade de vida, visando englobar saúde, bem-estar, segurança física, mental, social e disposição dos equipamentos para a realização das atividades laborais (KLEIN et al., 2019). Quando questionadas sobre o ambiente laboral, $70 \%$ das mulheres disseram considerá-lo bom, mas, destas, 53\% admitem que é possível melhorá-lo ainda mais.

Dentre as possibilidades de melhoria, as mulheres reafirmaram a questão de não haver registro em carteira e, mais especificamente, a falta de transparência e organização da equipe gestora dos serviços; questões de falta de comunicação e relacionamento interpessoal entre os colegas e o fato de que a população da cidade parece não colaborar com a separação do lixo, encaminhando material orgânico e, até mesmo, materiais perfurocortantes.

Acho que tinha de melhorar, as pessoas deveriam colaborar mais, porque jogam lixo orgânico no meio do reciclado (R., 20 anos)

Só precisava melhorar a quantidade de reciclável que é pouco e o povo aprender a reciclar, porque eles jogam muita comida junto com o reciclado (M., 21 anos).

Hoje a maior dificuldade é a falta de material. Está faltando. A gente devia estar recebendo no mínimo dez caminhões por dia, estamos recebendo seis (V., 37 anos).

Os pontos elencados são alguns dos que dificultam o cotidiano de trabalho das 
coletoras, segundo elas. Nesse sentido, o fenômeno pode estar relacionado com o que foi abordado anteriormente sobre a falta de incentivo das políticas públicas relacionadas à atividade de coleta de recicláveis, em consonância com estudos sobre o tema. Ressalte-se ainda a pouca atenção que a sociedade em geral dispensa à atividade de coleta e reciclagem de materiais e, por conseguinte, aos trabalhadores do setor.

\section{Catadoras de recicláveis e o preconceito}

As questões de números três e quatro da entrevista estruturada visavam compreender quais as percepções das participantes acerca das dificuldades de ser mulher e catadora de recicláveis e verificar se estas sentiam-se alvos de preconceito em função da classe a que pertencem. As perguntas foram, respectivamente: "Você sofre preconceito devido ao seu trabalho de coletora de reciclável?" e "Qual é a maior dificuldade que este trabalho apresenta?".

A maioria, 53\%, afirmou não sofrer preconceito especificamente pela função de coletora, mas sim pela pobreza, que as marginaliza; $47 \%$ afirmaram que sofrem preconceito, pois os coletores, homens e mulheres, são tratados com desconsideração. Quanto às dificuldades, citaram mais de uma opção, tendo sido as mais expressivas o relacionamento interpessoal, devido as fofocas e intrigas envolvendo homens e mulheres; responsáveis e subordinados; os gastos com deslocamento de casa para o trabalho, que compromete o orçamento final; o mau cheiro do local e a quantidade cada vez menor de produtos a serem reciclados, que impacta negativamente nos ganhos.

O preconceito foi mencionado como sendo a maior dificuldade a ser enfrentada no relacionamento com parentes, vizinhos, amigos e conhecidos; procedentes, portanto, de pessoas fora do universo de trabalho.

As pessoas me perguntam: "Como você tem coragem de trabalhar num serviço como esse? Não tem outro serviço melhor? Trabalhar no lixão!!!" (J., 29 anos).

Eu arrumei um emprego aqui para o meu irmão e ele disse: "Ah, eu não vou trabalhar naquele lixão, naquela nojeira". Eu me senti magoada, não respondi nada. Ficou guardado no meu coração. Minha mãe também trabalha na reciclagem, mas ela coleta na rua [...] as pessoas olham para a gente com nojo, desfazendo (L., 49 anos).

As pessoas falam: "você tem o segundo ano do ensino médio, poderia estar num serviço melhor, lá é sujo, não é para você" (K., 20 anos).

Perguntaram se eu não tenho vergonha (RO., 34 anos).

Apesar do trabalho aparecer no imaginário social como algo dignificante, a atividade de catadora de reciclável não é vista com bons olhos e, na verdade, não oferece plena possibilidade de inclusão social. A função é desqualificada, considerada suja e causa nojo às pessoas. É possível, assim, imaginar o quão terrível é a situação de quem exerce este ofício, pois não bastasse exercer esta atividade sob condições muitas vezes arriscadas, em locais insalubres, sem a garantia de direitos trabalhistas, ainda sofrem violência simbólica. Para além de toda a complexidade que envolve a desigualdade e suas consequências no campo dos preconceitos, a atividade exercida 
pelas catadoras de recicláveis é estigmatizada, devido, sobretudo, ao envolvimento com material descartado e do qual todos querem se livrar, fazendo com que a figura da catadora seja também associada ao próprio 'lixo'” (NASCIMENTO, 2016, p. 173). Para Lima e Trindade (2018), todos os fatores corroboram para que a atividade seja percebida culturalmente como marginalizada e desonrosa, fortificando, assim, a visão preconceituosa em relação à atividade de catação.

\section{Discriminação e/ou violência por motivo de gênero}

A pergunta 10 da entrevista estruturada teve como objetivo compreender o que as voluntárias consideravam um ato de violência contra a mulher, e os resultados demonstraram que $65 \%$ das entrevistadas compreendem especialmente a agressão física como sendo um ato de violência contra a mulher; $47 \%$ indicaram a violência verbal; $18 \%$ o feminicídio; $12 \%$ o assédio; $12 \%$ a violência sexual; $6 \%$ a traição e $6 \%$ citaram qualquer forma de discriminação contra as mulheres como sendo também uma violência. Assim, evidencia-se uma boa compreensão acerca do que seja um ato de violência contra as mulheres, uma vez que as entrevistadas não se limitaram à descrição de abusos físicos, mas também destacaram aspectos mais subjetivos.

Devido à sua construção social e histórica, a sociedade brasileira é profundamente patriarcal, com enraizamento dos papéis de gênero, isto é, formas de ser homem e ser mulher. Mesmo que a Constituição Brasileira de 1988 defina a obrigatoriedade da igualdade entre homens e mulheres, a realidade está ainda distante dessa conquista (BRASIL, 2002).

Nesse contexto, a família tornou-se, por excelência, o espaço da desigualdade. Naturalizou-se o ser homem e o ser mulher, desconsiderando aspectos culturais que modelam os papéis de gênero: mulheres são frágeis e submissas, enquanto homens são fortes, agressivos e provedores (exemplo esse que pode ser considerado real sob a perspectiva da interpretação simbólica aprendida culturalmente durante anos pela sociedade brasileira). É este contexto que ainda hoje valida a violência do homem contra a mulher, interpretada como natural (BRASIL, 2002).

A questão nove, por sua vez, teve como objetivo identificar se as voluntárias sentiram que algum homem próximo do núcleo familiar as tratava ou já as tinham tratado de maneira discriminatória por serem mulheres. À pergunta: "Em casa, você sente que seu marido/companheiro/pai/irmão the trata de forma violenta por ser mulher?" De acordo com os dados analisados, $47 \%$ das mulheres relataram não terem sofrido nenhum tipo de violência por serem mulheres; $47 \%$ disseram terem sofrido ou presenciado outra mulher da família sofrer violência e 6\% não responderam. Quando questionadas sobre a "razão", $37 \%$ das respondentes associaram as agressões ao fato do parceiro ser usuário de álcool; $25 \%$ relacionaram a violência ao ciúme do companheiro; $25 \%$ associaram a violência com o fato delas terem reclamado de infidelidade do companheiro. Ainda, $13 \%$ citaram causas diversas, como nervoso, maldade, gênio ruim, gostar de mandar, etc.

Ele é machista. Falas coisas, essas conversas de homem. Quando briga diz que mulher é isto, é aquilo. Ele tem vinte anos. Ele é bem nervoso [...]. As coisas não dâo certo para ele, ele desconta em mim e na avó dele. Xingando, mas nunca agrediu (sic). Ele fala que eu e a avó dele é que temos de tomar remédio (R., 20 anos). 


\begin{abstract}
Ele batia. Sou separada, vivi 17 anos com ele, mas não casei no papel não. Daí eu larguei dele, ele bebia muito [...] ele judiava muito de nós, aí eu separei dele e criei meus filhos tudo sozinha. Ele nunca me deu nada para as crianças [...] eu desisti desse homem para ele da pensão pras crianças. Não adianta. Cuido sozinha dos meus filhos (G., 43 anos).

No final do dia sobra tudo para mim [os trabalhos domésticos]. O meu filho mais velho fica com o banheiro, mas ele só lava uma vez no final de semana, mas nos outros dias quem limpa sou eu. O mais novo lava a louça, eu fico com a roupa e a casa, o meu marido fica com a comida, mas tem dia que ele está muito cansado e eu vou para o fogão. Quando ninguém quer, acaba sobrando tudo para mim (RO., 39 anos).
\end{abstract}

Observe, na fala de R, 20 anos, que esta entrevistada não identifica agressões verbais (xingamentos) como sendo efetivamente uma forma de violência. De fato, "nem sempre as situações de humilhações, agressões verbais e ameaças [...] são reconhecidas como formas de agressão tão graves quanto aquelas que atingem as mulheres física e sexualmente" (ZANCAN et al., 2019, p. 699). A fala de RO, por sua vez, vem reforçar o que já se sabe acerca do trabalho doméstico. Trata-se de uma atividade tida como obrigação das mulheres e que, para os homens, é entendida como uma "ajuda" que se dá quando quer.

\title{
Saúde $\mathrm{x}$ violência
}

Sobre como as mulheres se sentiram ao sofrer violência no ambiente doméstico, $62 \%$, ou seja, a maioria, relatou ter tido impactos psicológicos e/ou emocionais decorrentes do ato e $25 \%$ relataram impactos físicos intimamente relacionados com a agressão física. Apesar de $76 \%$ das mulheres afirmarem achar que a violência pode causar adoecimento, afirmaram ter boa saúde; $24 \%$ associaram seus problemas de saúde com o fato de terem sofrido algum tipo de violência ou ter presenciado atos de violência contra alguma mulher próxima, como mãe, filha ou irmã. Contudo, as respostas evidenciam que o sentido de "ter boa saúde" não quer dizer, necessariamente, não ter doença, já que 29\% apontaram apresentar dificuldades psicológicas e emocionais, como tristeza frequente, angústia, ansiedade, com comprometimento da qualidade de vida. O conceito se aproxima daquele proposto pela Organização Mundial da Saúde para quem, de fato, saúde não é ausência de doença (OMS citado por SILVA et al., 2018).

Este fato mostra o quanto apesar de haver consciência de que a violência é um elemento tensionador que produz riscos para a saúde, seja quando atinge diretamente a vítima ou alguém próximo, é difícil para a mulher identificar de maneira clara o grau de vulnerabilidade a que se encontra efetivamente exposta. Isto evidencia a importância de a discussão sobre a violência de gênero contra as mulheres estar atrelada às demandas do feminismo contemporâneo, mais atento às interseccionalidades de gênero, raça, etnia, geração, etc.

Segundo Gomes et al. (2014), a marca da violência sobre a saúde da mulher ultrapassa o campo do visível, podendo causar depressão, isolamento, ansiedade, 
baixo autoestima, ideação suicida. Como foi possível observar nas falas de algumas entrevistadas:

\begin{abstract}
Eu estava ficando louca [...] eu não dormia, eu não comia, eu tava ficando dessa finurinha [mostrou o dedo mindinho] se você visse [...] Atualmente minha saúde está até boa, porque tenho sossego, sossego pra dormir, pra acordar e vir trabalhar (G., 43 anos).
\end{abstract}

Eu emagreci muito, não comia, me deu depressão, até hoje tenho de tomar remédio controlado [...] de repente, me dava uma choradeira [...] eu tenho muita dor de cabeça. Fui à psicóloga e ela disse que isso era convulsão e fui ao médico e ele disse que era nervoso. Entortava todos os meus nervos [vira os braços e pulsos na tentativa de representar] (L., 49 anos).

Desde os anos 1990, a Organização Mundial da Saúde (OMS) reconhece a violência contra as mulheres como um problema de saúde pública, com consequências que permanecem mesmo quando os agravos cessam de ocorrer. Uma série de doenças físicas e psíquicas podem estar associadas à violência, tais como diarreias; mau funcionamento do intestino; infecções urinárias; dores musculares incapacitantes; fibromialgia; úlceras; gastrites; doenças sexualmente transmissíveis; aids; gravidez indesejada; abortos; distúrbios do sono; depressão; ansiedade; medos e pânicos. Além disso, mulheres que sofrem violência têm mais dificuldade de cuidar de si e dos outros que estão sob suas responsabilidades, como idosos e crianças. O número de mulheres que realiza cirurgia, procura os médicos e que tem insucesso em seus tratamentos de saúde é maior entre as que sofrem violência (SCHRAIBER et al., 2005).

A violência contra as mulheres, seja física ou psicológica, quer ocorra no ambiente laboral ou doméstico, não compromete apenas a saúde e a qualidade de vida das mulheres, seus filhos ou familiares próximos, mas produz agravos que se estendem a toda estrutura da sociedade, à medida que afronta inúmeros instrumentos internacionais de valorização da dignidade da pessoa humana.

\title{
CONCLUSÕES
}

Os resultados apresentados e discutidos neste artigo, demonstram a vulnerabilidade social das catadoras de materiais recicláveis que atuam em duas cooperativas de Maringá. Contudo, é bastante plausível supor que as situações descritas por elas não diferem da realidade das demais mulheres que exercem a semelhante atividade em outras cooperativas do município analisado e mesmo em diferentes cidades e países.

Foi possível perceber que estas mulheres enfrentam dificuldades no trabalho e na vida cotidiana, seja em razão das desigualdades de gênero, seja porque exercem uma função socialmente desvalorizada, mesmo que, conforme observado, nem todas tenham plena consciência disso. É importante refletir sobre estas questões, tendo em vista que preconceito e discriminação são elementos que comprometem a saúde, a qualidade de vida das pessoas e afrontam a dignidade humana. Ser coletora de materiais recicláveis é um estigma que carregam.

Frente a isso, vale destacar a importância das pesquisas metodologicamente sustentadas em narrativas, pois estas nos oportunizam o acesso às experiências dos 
indivíduos, reconhecendo o protagonismo daquelas/es normalmente à margem da sociedade e, até há pouco tempo, ausentes dos estudos científicos, menos interessados naqueles que estão na franja da sociedade.

Nesse sentido, o que as falas de nossas entrevistas apontam é a necessidade de que mais esforços sejam dispensados pelos diversos setores para garantir melhores de trabalho, incluindo o reconhecimento de direitos trabalhistas, e melhores condições de vida e saúde para essas trabalhadoras, especialmente, através do fortalecimento das comunidades, cooperativas, Organizações Não Governamentais e outros grupos atentos aos direitos humanos.

\section{REFERÊNCIAS}

ADERALDO, C.V.L; AQUINO, C.A.B; SEVERIANO, M.F.V. Aceleração, tempo social e cultura do consumo: notas sobre as (im)possibilidades no campo das experiências humanas. Caderno EBAPE.BR, v. 18, no 2, Rio de Janeiro, Abr./Jun. 2020. Disponível em https://www.scielo.br/j/cebape/a/Vq8CxsJ6xpwcyjGt9SqMgBz/?format=pdf\&lang=pt. DOI: http://dx.doi.org/10.1590/1679-395177662.

ANTUNES, R.; PRAUN, L. A sociedade dos adoecimentos no trabalho. Serviço Social \& Sociedade, São Paulo, n. 123, p. 407-427, 2015. Disponível em: https://www.scielo.br/j/sssoc/a/cbc3JDzDvxTqK6SDTQzJJLP/?lang=pt\&format=pdf. doi: https://doi.org/10.1590/0101-6628.030

BARBOSA, M. F. N.; SILVA, M. M. P.; SOUZA, M. A. Os catadores de materiais recicláveis e sua luta pela inclusão e reconhecimento social no período de 1980 a 2013. Revista Monografias Ambientais - REMOA, Santa Maria-RS, v. 13, n. 5, p. 39984010, dez 2014. Disponível em: https://periodicos.ufsm.br/remoa/article/view/15145. doi: https://doi.org/10.5902/2236130815145.

BARDIN, L. Análise de conteúdo. São Paulo: Edições 70, 2016.

BRASIL. Ministério da Saúde. Violência intrafamiliar: orientações para práticas em serviço. Brasília: Ministério da Saúde, 2002. 96p. (Cadernos de Atenção Básica, 8; Série A - Normas e Manuais Técnicos, no 131). Disponível em: https://bvsms.saude.gov.br/bvs/publicacoes/cd05_19.pdf. Acesso em: 20 jan. 2020.

CARDANO, M. Manual de pesquisa qualitativa: a contribuição da teoria da argumentação. Tradução Elisabeth da Rosa Conil. Petrópolis, RJ: Vozes, 2017.

COELHO, A. P. F.; BECK, C. L. C.; FERNANDES, M. N. S.; PRESTES, F. C.; SILVA, R. $M$. Risco de adoecimento relacionado ao trabalho e estratégias defensivas de mulheres catadoras de materiais recicláveis. Escola Anna Nery, Rio de Janeiro, v. 20, n. 3, e20160075, jul./set. 2016.2 Disponível em: https://www.scielo.br/j/ean/a/JxFzGBWRZdM73dSkJwnKtYq/abstract/?lang=pt. doi: https://doi.org/10.5935/1414-8145.20160075.

COSTA, W. B.; CHAVES, M. R. Catadores de recicláveis: entre a informalidade e a precarização do trabalho. Espaço em revista, Catalão-GO, v. 15, n. 1, p. 143-155, 
2013. Disponível em: https://www.revistas.ufg.br/espaco/article/view/26195/15085. doi: https://doi.org/10.5216/er.v15i1.26195.

DIAS, M. L. F. G.; JUNQUEIRA, L. A. P.; MOURA, L. R. Um olhar sobre a saúde do catador de material reciclável: uma proposta de quadro analítico. Ambiente \& Sociedade: Temas em Destaque, São Paulo, v. 21, p. 1-20, 2018. Disponível em: https://www.scielo.br/j/asoc/a/X3hF3cbFvHXnjTC7tZnKVYN/abstract/?lang=pt. doi: https://doi.org/10.1590/1809-4422asoc0107r2vu18L1AO.

FONTANA, R. T.; RIECHEL, B.; FREITAS, C. W.; FREITAS, N. A saúde do trabalhador da reciclagem do resíduo urbano. Vigilância Sanitária em Debate: Sociedade, Ciência \& Tecnologia, v. 3, n. 2, p. 29-35, 2015. Disponível em: https://visaemdebate.incqs.fiocruz.br/index.php/visaemdebate/article/view/292/216. doi: https://doi.org/10.3395/2317-269x.00292.

GIL, A. C. Métodos e técnicas de pesquisa social. 6. ed. São Paulo, SP: Atlas, 2008.

GOMES, N. P.; ERDMANN, A. L.; STULP, K. P.; DINIZ, N. M. F.; CORREIA, C. M. et al. Cuidado às mulheres em situação de violência conjugal: importância do psicólogo na Estratégia de Saúde da Família. Psicologia, USP, São Paulo, v. 25, n. 1, p. 63-69, $2014 . \quad$ Disponível em: https://www.scielo.br/j/pusp/a/j53JvdHqMh3Q6xB4CxCbsQN/?lang=pt. https://doi.org/10.1590/S0103-65642014000100007

KLEIN, L. L.; PEREIRA, B. A. D.; LEMOS, R. B. Quality of working life: parameters and evaluation in the public service. Ram. Revista de Administração Mackenzie [online], São Paulo, v. 20, n. 3, 2019. Disponível em: https://www.scielo.br/j/ram/a/V8HdXZYdMG9f6r8h5mCNs4g/?lang=en. doi: https://doi.org/10.1590/1678-6971/eRAMG190134.

LIMA, M. E.; TRINDADE, I. O sentido do trabalho no contexto da atividade do catador de material reciclável: um estudo de caso. Cadernos de Psicologia Social do Trabalho, São Paulo, v. 21, n. 1, p. 33-43, jun. 2018. Disponível em: http://pepsic.bvsalud.org/scielo.php?script=sci_arttext\&pid=S1516-

37172018000100003\&lng=pt\&nrm=iso. doi: http://dx.doi.org/10.11606/issn.19810490.v21i1p33-43.

MEIHY, J. C. S. B.; SEAWRHIGHT, L. Memórias e narrativas: história oral aplicada. São Paulo: Contexto, 2020.

MNCR - Movimento Nacional dos Catadores de Materiais Recicláveis - Mulheres são maioria entre Catadores de Materiais Recicláveis. São Paulo, 21 mar. 2014. Disponível em: http://www.mncr.org.br/noticias/noticias-regionais/mulheres-sao-maioriaentre-catadores-organizados-em-cooperativas. Acesso em:

MNCR - Movimento Nacional dos Catadores de Materiais Recicláveis - Quantos Catadores existem em atividade no Brasil? São Paulo, 10 abr. 2019. Disponível em: 
http://www.mncr.org.br/sobre-o-mncr/duvidas-frequentes/quantos-catadores-existemem-atividade-no-

brasil\#: :text=Os\%20catadores\%20s\%C3\%A3o\%20respons\%C3\%A1veis\%20pela,da\% 20Bahia\%20\%E2\%80\%93\%20GERI\%2C\%202006.

NASCIMENTO, J. B. Burros sem rabo: invisibilidade e consumo ostensivo. Curitiba: Appris, cap. 2.2, p. 157-192, 2016.

ODDONE, I.; GASTONE, M.; GLORIA, S.; BRIANTE, G.; CHIATELLA, M. et al. Ambiente de trabalho: a luta dos trabalhadores pela saúde. Tradução Salvador Obiol de Freitas. 2. ed. São Paulo: Hucitec, 2020.

OLIVEIRA, D. A. M.; MORAES, L. R. S.; TRAD, S. Riscos ocupacionais na coleta de materiais recicláveis: percepção e condicionantes em uma cooperativa familiar. In: LIMA, M. A. G.; FREITAS, M. C. S.; PENA, P. G. L.; TRAD, S. (org.). Estudos de saúde, ambiente e trabalho: aspectos socioculturais. Salvador: Ed. da EDUFBA, 2017, p. 175190. Disponível em: http://books.scielo.org/id/sdytq/pdf/lima-9788523218645-10.pdf. doi: http://doi.org/10.7476/9788523218645.0010.

PEREIRA, J. C. S.; GODOI, C. K.; COELHO, A. L. A. L. Qualidade de vida dos catadores de materiais recicláveis: um estudo etnográfico. Gestão e Sociedade Revista Eletrônica, Belo Horizonte, v. 6, n. 14, p. 159-177, maio/ago. 2012. Disponível em: https://www.gestaoesociedade.org/gestaoesociedade/article/view/1362. Doi: https://doi.org/10.21171/ges.v6i14.1362

POCHEMAN, M. Tendências estruturais do mundo do trabalho no Brasil. Ciência \& Saúde Coletiva, v. 25, n. 1, p. 89-99, jan. 2020. Disponível em https://www.scielo.br/j/csc/a/vnJWDbvYCwqdYdVypqrJMBm/abstract/?lang=pt. doi: https://doi.org/10.1590/1413-81232020251.29562019.

SCHRAIBER, L. B.; D'OLIVEIRA, A. F. P. L.; FALCÃO, M. T. C.; FIGUEIREDO, W. S. Violência dói e não é direito: a violência contra as mulheres, a saúde e os direitos humanos. São Paulo: Ed. da Unesp, 2005. 184p.

SILVA, T. M. G.; MARQUES, A. G.; PRIORI, C.; HEIL, G. G. Pode-se ter saúde e qualidade de vida em situação de violência e desrespeito aos direitos humanos? Uma reflexão à luz dos estudos feministas e de gênero. Revista Tempo, Espaço e Linguagem, Irati, v. 9, n. 2, p. 129-149, dez. 2018. Disponível em: https://revistas2.uepg.br/index.php/tel/article/view/12321/209209210622. doi: https://doi.org/10.5935/2177-6644.20180019

SOUZA, D. O.; SANTOS, L. B. Nexo biopsíquico humano no contexto dos catadores de lixo de uma associação do município de Arapiraca-AL. Physis: Revista de Saúde Coletiva, Rio de Janeiro, v. 30, n. 2, e300227, 2020. Disponível em https://www.scielosp.org/pdf/physis/2020.v30n2/e300227/pt. doi: http://dx.doi.org/10.1590/S0103-73312020300227. 
LIMA, M.S. Estudo da vulnerabilidade social dos catadores de materiais recicláveis no município de Tavares- PB. Revista Científica Multidisciplinar Núcleo do Conhecimento. Ano 06, Ed. 07, Vol. 07, pp. 152-185. Julho de 2021. ISSN: 24480959, Link de acesso: https://www.nucleodoconhecimento.com.br/cienciassociais/municipio-de-tavares

ZANCAN, N.; LAWRENZ, P.; CURIA, B. G.; HABIGZANG, L. F.; LIGORIO, I. S. et al. Histórico de violência e Transtornos de Estresse Extremo Não-Especificados (DESNOS) em mulheres. Contextos Clínicos, São Paulo, v. 12, n. 2, 2019. Disponível em: http://pepsic.bvsalud.org/pdf/cclin/v12n2/v12n2a15.pdf. doi: http://dx.doi.org/10.4013/ctc.2019.122.14. 